\title{
PENGARUH PENDIDIKAN KESEHATAN TERHADAP PENGETAHUAN TENTANG PERSONAL HYGIENE PADA ANAK USIA SEKOLAH DI SDN 206/IV KOTA JAMBI
}

\author{
Tina Yuli Fatmawati \\ Prodi DIII Keperawatan STIKes Baiturrahim Jambi \\ Email:tinayulifatmawati@yahoo.com
}

\begin{abstract}
Health problems that often occur in elementary school age children are diseases related to child and environmental hygiene such as brushing teeth is good and right, the habit of washing hands with soap and personal hygiene. This studi aim to know to determine whether there is influence of health education to the knowledge of school-aged children about Personal Hygiene at SDN 206 / IV Kota Jambi. This research is a quantitative research using One Group pretest-posttest design. The research was carried out at SDN 206 / IV Kota Jambi in June 2017. The population is Students SDN 206 / IV Kota Jambi with a sample of 20 students. Data analysis using univariate and bivariate analysis with statistical test of $T$ dependent. The result of this research is $p$-value $=0,00<0,05$ with difference of mean value 2.35. This indicates there is a significant influence between the knowledge of the respondents before and after being given health education.
\end{abstract}

Keywords: Health education, Students, Personal Hygiene

\begin{abstract}
ABSTRAK
Masalah - masalah kesehatan yang sering terjadi pada anak usia sekolah dasar adalah penyakit yang berhubungan dengan kebersihan diri anak dan lingkungan seperti gosok gigi yang baik dan benar, kebiasaan mencuci tangan pakai sabun dan kebersihan diri. Tujuan dari penelitian ini adalah untuk mengetahui apakah ada pengaruh pendidikan kesehatan terhadap pengetahuan anak usia sekolah tentang Personal Hygiene di SDN 206/IV Kota Jambi . Penelitian ini merupakan penelitian kuantitatif dengan menggunakan rancangan One Group pretest-posttest . Penelitian dilaksanakan di SDN 206/IV Kota Jambi pada bulan Juni 2017. Populasi yaitu Siswa Sekolah Dasar Negeri 206/IV Kota Jambi dengan jumlah sampel 20 siswa. Analisis data menggunakan analisa univariat dan bivariat dengan uji statistik T Test. Hasil penelitian diperoleh nilai $p$-value $=0,00<0,05$ dengan selisih nilai mean -2.35 . Hal ini menunjukkan ada pengaruh yang signifikan antara pengetahuan responden sebelum dengan setelah diberikan pendidikan kesehatan .
\end{abstract}

Kata Kunci: Pendidikan kesehatan, Siswa/i, Personal Hygiene 


\section{PENDAHULUAN}

Memasuki usia sekolah dasar adalah waktu sangat penting bagi kelangsungan perkembangan anak. Dukungan orang tua, guru dan masyarakat merupakan hal yang sangat penting (Depkes RI 2010). Masalah masalah kesehatan yang sering terjadi pada anak usia sekolah dasar adalah penyakit yang berhubungan dengan kebersihan diri anak dan lingkungan seperti gosok gigi yang baik dan benar, kebiasaan cuci tangan pakai sabun, dan kebersihan diri. Penyakit yang sering muncul adalah diare, kecacingan, sakit gigi dan lain sebagainya (Saputra, 2013)

Kebersihan diri (personal hygiene) merupakan perawatan diri sendiri yaang dilakukan untuk mempertahankan kesehatan, baik secara fisik maupun psikologis. Hidayat (2009. Personal hygiene merupakan kebutuhan dasar manusia yang harus senantiasa terpenuhi. Personal hygiene termasuk kedalam tindakan pencegahan primer yang spesifik. Personal hygiene menjadi sangat penting karena personal hygiene yang baik akan meminimalkan pintu masuk ( port de entry) mikroorganisme yang ada dimana-mana dan pada akhirnya mencegah seseorang terkena penyakit. (Saryono, 2011)

Data yang menyangkut personal hygiene masih kurang, berdasarkan data dari Depkes RI tahun 2011 kejadian pravalensi kasus kecacingan pada anak SD di Indonesia sebanyak $24,1 \%$. Berdasarkan hasil survei kecacingan oleh Ditjen Pengendalian Penyakit dan Penyehatan Lingkungan (P2PL) Departemen Kesehatan tahun 2009 menyebutkan $31,8 \%$ siswa sekolah dasar di Indonesia mengalami kecacingan (Depkes RI, 2008). Sedangkan untuk penyakit kulit yang paling sering menimbulkan masalah adalah penyakit infeksi kulit, bedasarkan data Departemen Kesehatan RI tahun 2011, $65 \%$ penyakit kulit menyerang penduduk pedesaan, ini disebabkan oleh kondisi lingkungan yang kotor dan perilaku hidup masyarakat yang tidak sehat, (Depkes RI, 2011).

Penelitian sebelumnya yang dilakukan oleh Fatmawati, 2017, tentang Pengetahuan, Sikap, Dan Perilaku SiswaSiswi Tentang Personal Hygiene Di Sd Negeri Kota Jambi, diperoleh $48 \%$ responden masih berperilaku kurang baik terhadap personal hygiena. Ini artinya masih banyak siswa siswi SD yang masih berperilaku kurang baik dalam personal hygiena. Sedangkan Fatim (2012) yang meneliti tentang "Pengaruh Pendidikan Kesehatan tentang Personal Hygiene terhadap Tingkat pengetahuan dan Perilaku Personal Hygiene Pada Anak Usia Sekolah di Shelter Dongkelsari dan Ploso Kerep Cangkringan Sleman Yogyakarta" didapatkan hasil pengetahuan tentang personal hygiene pada kelompok eksperimen dengan nilai $\mathrm{p}=0,003$, sedangkan untuk perilaku personal hygiene didapatkan $\mathrm{p}=0,005$. Hasil tersebut menunjukkan bahwa terdapat perbedaan yang signifikan antara pengetahuan sebelum dan sesudah diberikan pendidikan kesehatan.

Begitu juga halnya Nurjannah, 2012, dalam penelitiannya tentang Personal Hygiene Siswa Sekolah Dasar Negeri Jatinangor, diperoleh personal hygiene secara keseluruhan sebanyak 3,2\% responden termasuk kedalam kategori hygiene kurang dan 96,8\% tidak hygiene. Hal ini menunjukkan masih banyak siswa/siswi SD yang belum memahami pentingnya kebersihan diri.

Laporan Riset Kesehatan (RISKESDA) Provinsi Jambi tahun 2013 angka kejadian penyakit kulit di provinsi jambi 27/1000 penduduk, sedangkan untuk masalah kesehatan gigi dan mulut penduduk provinsi Jambi mempunyai masalah gigi dan mulut sebesar 25,1 \% . Kabupaten 
Sarolangun menduduki peringkat tertinggi untuk masalah kesehatan gigi dan mulut sebesar 38, 3\% dan terendah di kabupaten Merangin dengan 15,4 \%. Kota Jambi menduduki peringkat ke-6 untuk jumlah prevalensi masalah kesehatan gigi dan mulut (Depkes RI, 2012).

Survey awal yang dilakukan peneliti dengan wawancara kepada 5 orang siswasiwi kelas 5 di SDN 206/IV Kota Jambi didapatkan 3 anak tidak mengetahui cara menjaga kebersihan diri secara menyeluruh, sedangkan 2 anak lagi telah melakukan personal hygiene yang baik dan mengetahui cara menjaga kesehatan diri sendiri seperti mandi 2 kali sehari, mencuci tangan dengan sabun,memotong kuku seminggu sekali, sedangkan dari wawancara dengan salah satu guru menyampaikan bahawa jarang sekali dilakukan penyuluhan kesehatan oleh petugas UKS maupun Petugas dari Puskesmas terutama mengenai pentingnya kebersihan diri. Sedangkan dari observasi didapatkan sebagian besar siswa tidak mencuci tangan sebelum makan jajanan dan minimnya poster tentang kebersihan diri.

Berdasarkan fenomena dan data diatas peneliti tertarik untuk melakukan penelitian yang berjudul "Pengaruh pendidikan kesehatan terhadap pengetahuan tentang personal hygiene pada anak usia sekolah di SDN 206/IV Kota Jambi”.

\section{METODE PENELITIAN}

Penelitian ini merupakan penelitian pra eksperimen dengan menggunakan rancangan One Group pretest-posttest. One Group pretest-post test adalah rancangan yang hanya menggunakan satu kelompok tanpa menggunakan kelompok pembanding tetapi yang diuji adalah perubahanperubahan yang terjadi setelah diberikan pendidikan kesehatan. Penelitian ini telah dilaksanakan pada bulan Juni 2017 dengan menggunakan teknik purposive sampling.
Populasi pada penelitian ini yaitu Siswa Sekolah Dasar Negeri SDN 206/IV Kota Jambi kelas $\mathrm{V}$ dengan jumlah sampel sebanyak 20 responden. Instrumen penelitian yang digunakan dalam penelitian ini adalah kuesioner untuk mengetahui perubahan pengetahuan tentang Personal Hygiene pada anak usia sekolah di SDN 206/IV Kota Jambi. Media yang digunakan dalam penelitian ini adalah modul dan leaflet.

\section{HASIL DAN PEMBAHASAN}

Tabel 1. Distribusi Frekuensi responden Berdasarkan Umur di SDN 206 Kota Jambi.

\begin{tabular}{cccc}
\hline No & $\begin{array}{c}\text { Umur } \\
\text { siswa/i }\end{array}$ & Jumlah & $\mathbf{( \% )}$ \\
\hline 1 & 10 Tahun & 7 & 35.0 \\
2 & $11-12$ & 13 & 65.0 \\
& Tahun & 20 & 100 \\
\hline
\end{tabular}

Berdasarkan tabel diatas diketahui bahwa dari 20 responden, 13 responden $(65.0 \%)$ berumur 11-12 tahun, 7 responden $(35.0 \%)$ berumur 10 tahun

Tabel 2. Distribusi Frekuensi Responden Berdasarkan Jenis Kelamin di SDN 206 Kota Jambi .

\begin{tabular}{cccc}
\hline No & $\begin{array}{c}\text { Jenis } \\
\text { Kelamin }\end{array}$ & Jumlah & $\mathbf{( \% )}$ \\
\hline 1 & Laki-laki & 16 & 80.0 \\
2 & Perempuan & 4 & 20.0 \\
& Total & 20 & 100 \\
\hline
\end{tabular}

Berdasarkan tabel diatas dapat diketahui Jenis Kelamin responden terbanyak adalah laki-laki 16 responden $(80.0 \%)$.

\section{Analisi univariat}


Gambaran pengetahuan siswa Sebelum dan Sesudah Diberikan Pendidikan Kesehatan Tentang personal hygiena

Secara garis besar berikut ini disampaikan hasil gambaran pengetahuan tentang kebersihan diri pada siswa/siswi usia sekolah sebelum dan sesudah di berikan pendidikan kesehatan:

\begin{tabular}{lccc}
$\begin{array}{l}\text { Tabel } \\
\begin{array}{l}\text { Pengetahuan } \\
\text { diberikan pendidikan kesehatan } \\
\text { 206 }\end{array}\end{array}$ & $\begin{array}{c}\text { Distribusi } \\
\text { Responden }\end{array}$ & $\begin{array}{r}\text { Frekuensi } \\
\text { sebelum } \\
\text { di SDN }\end{array}$ \\
\hline No & Pengetahuan & Jumlah & $(\boldsymbol{\%})$ \\
\hline 1. & Baik & 12 & 60.0 \\
2. & Kurang & 8 & 40.0 \\
& Total & $\mathbf{2 0}$ & $\mathbf{1 0 0 , 0}$ \\
\hline
\end{tabular}

Berdasarkan tabel diatas diketahui bahwa dari 20 Responden sebagian besar responden (60.0\%) mempunyai pengetahuan baik sebelum diberikan pendidikan kesehatan, sedangkan $40.0 \%$ responden yang kurang baik.

Tabel 4. Distribusi Frekuensi Pengetahuan Responden setelah diberikan pendidikan kesehatan di SDN 206

\begin{tabular}{cccl}
\hline No & Pengetahuan & Jumlah & $\mathbf{( \% )}$ \\
\hline 1. & Baik & 15 & 75.0 \\
2. & Kurang & 5 & 25.0 \\
& Total & $\mathbf{2 0}$ & $\mathbf{1 0 0}$ \\
& & & $\mathbf{0}$ \\
\hline
\end{tabular}

Berdasarkan tabel diatas diketahui bahwa dari 20 Responden sebagian besar responden (75.0\%) mempunyai pengetahuan baik setelah diberikan pendidikan kesehatan, sedangkan $25.0 \%$ responden yang masih kurang baik.

\section{Analisa Bivariat}

Berdasarkan hasil penelitian dapat diketahui pengaruh pendidikan kesehatan tentang
Kebersihan diri di SDN 206 tahun 2016, dapat dilihat pada tabel dibawah ini:

Tabel 5. Perbedaan pendidikan kesehatan sebelum dan setelah diberikan pendidikan kesehatan tentang personal hygiene di SDN 206

\begin{tabular}{|c|c|c|c|c|c|}
\hline Variabel & $\begin{array}{c}\text { Mea } \\
\mathbf{n}\end{array}$ & SD & SE & $\begin{array}{c}\text { p- } \\
\text { Val } \\
\text { ue }\end{array}$ & $\mathbf{N}$ \\
\hline $\begin{array}{l}\text { Pengetahua } \\
\text { n Sebelum } \\
\text { Diberikan } \\
\text { Pendidikan } \\
\text { Kesehatan } \\
\text { (PRE } \\
\text { TEST) }\end{array}$ & 12.35 & $\begin{array}{c}2.77 \\
7\end{array}$ & $\begin{array}{c}0.62 \\
1\end{array}$ & \multirow{2}{*}{$\mathbf{0 , 0 0}$} & 20 \\
\hline $\begin{array}{l}\text { Pengetahua } \\
\text { n Sesudah } \\
\text { Diberikan } \\
\text { Pendidikan } \\
\text { Kesehatan } \\
\text { (POST } \\
\text { TEST) }\end{array}$ & 15.05 & $\begin{array}{c}0.94 \\
4\end{array}$ & $\begin{array}{c}0.21 \\
1\end{array}$ & & 20 \\
\hline \multicolumn{6}{|c|}{$\begin{array}{l}\text { Berdasarkan Tabel di atas } \\
\text { menunjukan bahwa rata-rata pengetahuan } \\
\text { responden sebelum mengikuti pendidikan } \\
\text { kesehatan adalah } 12.35 \text { dengan standar } \\
\text { deviasi } 2.777 \text { dan pengetahuan responden } \\
\text { setelah mengikuti pendidikan kesehatan } \\
\text { adalah } 15.05 \text { dengan standar deviasi } 0.944 \\
\text { dengan hasil uji T test di dapatkan nilai } p \text { - } \\
\text { value= } 0,00<0,05 \text { dengan selisih nilai } \\
\text { mean -2.70. Hal ini menunjukkan ada } \\
\text { pengaruh yang signifikan antara } \\
\text { pengetahuan responden sebelum dengan } \\
\text { setelah diberikan pendidikan kesehatan. }\end{array}$} \\
\hline
\end{tabular}

\section{Pembahasan}

Berdasarkan hasil penelitian diperoleh gambaran pengetahuan responden terjadi peningkatan pengetahuan sebelum dan sesudah diberikan pendidikan kesehatan tentang kebersihan diri pada siswa usia sekolah yaitu dari pengetahuan baik pretest 
$60 \%$ menjadi $75 \%$ responden berpengetahuan baik.

Adapun hasil uji $T$ test di dapatkan nilai $p$-value $=0,00<0,05$ dengan selisih nilai mean -2.35 . Hal ini menunjukkan ada pengaruh yang signifikan antara pengetahuan responden sebelum dengan setelah diberikan pendidikan kesehatan .

Sejalan dengan penelitian Aulia, 2014 tentang pengaruh pendidikan kesehatan tentang personal hygiene terhadap pengetahuan dan sikap di SDN Rembes I, didapatkan hasil $t$ test menunjukkan nilai $p$ value pada pengetahuan $0.003(<0.05)$ yang artinya ada pengaruh pendidikan kesehatan tentang personal hygiene terhadap pengetahuan siswa di SDN Rembes I.

Menurut Notoatmodjo (2012) pengetahuan adalah hasil dari penginderaan manusia atau hasil dari tahu seseorang terhadap objek melalui indera yang dimilikinya. Pendidikan Kesehatan sebagai bagian dari kesehatan masyarakat, berfungsi sebagai media atau sarana untuk menyediakan kondisi sosio-psikologi sedemikian rupa sehingga individu atau masyarakat berperilaku sesuai dengan norma-norma hidup sehat, dengan perkataan lain pendidikan kesehatan bertujuan mengubah pengetahuan, sikap dan tindakan individu atau masyarakat sehingga sesuai dengan norma-norma hidup sehat, pendidikan akan berpengaruh pada perilaku kesehatan, selanjutnya perilaku kesehatan akan berpengaruh pada meningkatnya indikator kesehatan masyarakat (outcome) pendidikan kesehatan.

Tujuan pendidikan kesehatan adalah mengubah perilaku orang atau masyarakat dari perilaku tidak sehat menjadi perilaku sehat, seperti kita ketahui bila perilaku tidak sesuai dengan prinsip kesehatan, maka dapat menyebabkan terjadinya gangguan terhadap kesehatan. (WHO dalam Susilo, 2011)

Dalam penelitian ini diketahui dari 20 responden bahwa pengetahuan responden sebelum diberikan pendidikan kesehatan masih rendah, hal ini terlihat dari gambaran jawaban pada saat pretest. Pengetahuan responden masih rendah terutama tentang tatacara kebersihan telinga dan kaki. Untuk itu upaya yang dapat dilakukan untuk membantu meningkatkan pengetahuan responden tentang personal hygiene pada siswa adalah dengan cara pemberian pendidikan kesehatan/ penyuluhan rutin yang dilaksanakan oleh guru maupun petugas UKS sehingga dapat meningkatkan pengetahuan siswa tentang personal hygiene dan mampu mendorong siswa untuk mengaplikasikannya dalam kehidupan sehari-hari.

Dalam penelitian ini diketahui dari 20 responden bahwa pengetahuan responden sebelum diberikan pendidikan kesehatan masih rendah, hal ini terlihat dari gambaran jawaban pada saat pretest. Pengetahuan responden masih rendah terutama tentang tatacara kebersihan telinga dan kaki. Untuk itu upaya yang dapat dilakukan untuk membantu meningkatkan pengetahuan responden tentang personal hygiene pada siswa adalah dengan cara pemberian pendidikan kesehatan/ penyuluhan secara rutin yang dilaksanakan oleh guru maupun petugas UKS sehingga dapat meningkatkan pengetahuan siswa tentang personal hygiene dan terus mendorong dan memantau siswa/siswi agar mau melaksanakannya dalam kehidupan sehari-hari.

\section{SIMPULAN}

Berdasarkan hasil penelitian diperoleh bahwa responden mengalami perubahan pengetahuan setelah diberikan pendidikan kesehatan tentang personal hygiene, lebih jelasnya dapat dilihat sebagai berikut :

1. Pengetahuan responden sebelum diberi pendidikan kesehatan sebagian besar responden $(60.0 \%)$ mempunyai pengetahuan baik, sedangkan $40.0 \%$ 
responden memiliki pengetahuan yang kurang baik.

2. Pengetahuan responden setelah diberikan pendidikan kesehatan sebagian besar responden (75.0\%) mempunyai pengetahuan baik, sedangkan $25.0 \%$ responden yang masih berpengetahuan kurang baik.

3. Hasil uji $t$ test diperoleh nilai $p$ value $=0,00<0,05$ dengan selisih nilai mean -2.70 . Hal ini menunjukkan ada pengaruh yang signifikan antara pengetahuan responden sebelum dengan setelah diberikan pendidikan kesehatan .

\section{SARAN}

\section{Bagi Sekolah}

Pada pihak Sekolah terutama guru dan petugas UKS untuk lebih sering melakukan penyuluhan /pendidikan kesehatan secara rutin serta terjadwal tentang pentingnya personal hygiene.

\section{Bagi siswa}

Diharapkan dapat meningkatkan pengetahuan tentang personal hygiene dan mau melaksanakan dalam kehidupan seharihari.

3. Bagi Peneliti Selanjutnya

Diharapkan bagi peneliti selanjutnya agar dapat melakukan penelitian lanjutan tentang Kebersihan diri dengan variabel dan metode yang berbeda.

\section{DAFTAR PUSTAKA}

Akmal. 2013. Hubungan Personal Hygiene dengan kejadian scabies di Pondok Pendidikan Islam Darul Ulum, Paralik Pacah, Kecamatan Koto Tangah Padang. Jurnal Keperawatan

Arikunto, S. 2007. Prosedur Penelitian Suatu Pendekatan Praktik. Jakarta : Rineka Cipta.
Aulia, Farah I, 2014, Pengaruh Pendidikan Kesehatan Tentang Personal Hygiene Terhadap Pengetahuan Dan Sikap Di SDN Rembes I, Jurusan keperawatan Univ Muh Surakarta.

Devi, N. 2012. Gizi Anak Sekolah. Kompas Media Nusantara. Jakarta

Depkes RI. 2010. Profil Kesehatan Indonesia. Jakarta

Depkes RI. 2011. Krida Bina Perilaku Hidup Bersih dan Sehat. Jakarta

Fatim. 2012. Pengaruh Pendidikan Kesehatan tentang Personal Hygiene pada anak usia sekolah di Shelther Dongkelsari dan Ploso Kenep Cangkringan Sleman Yogyakarta. Jurnal Keperawatan.

Fatmawati, T. Y. (2017). Pengetahuan, Sikap, Dan Perilaku Siswa-Siswi Tentang Personal Hygiene $\mathrm{Di} \quad \mathrm{Sd}$ Negeri Kota Jambi Knowledge, Attitude And Behavior Students About Hygiene Personal In Sdn Kota Jambi. Scientia Journal, 6(1). Retrieved from http://ejournal.unaja.ac.id/index.php?jo urnal $=$ SCJ $\&$ page $=$ article $\&$ op $=$ view $\& p$ ath $\% 5 \mathrm{~B} \% 5 \mathrm{D}=52 \&$ path $\% 5 \mathrm{~B} \% 5 \mathrm{D}=43$

Fitriani, S. 2011. Promosi Kesehatan. Graha Ilmu. Yogyakarta

Ghofur, A. 2012. Buku Pintar Kesehatan Gigi dan Mulut. Mitra Buku. Yogyakarta

Hidayat, A.A. 2009. Pengantar Ilmu Keperawatan Anak 1. Salemba Medika. Jakarta 
Kusumawardani, E. 2011. Buruknya Kesehatan Gigi dan Mulut. Siklus. Yogyakarta

Notoatmojo, 2012. Pendidikan dan Perilaku Kesehatan. Jakarta : Rieneka Cipta

Nursalam dan Effendi, F. 2008. Pendidikan Dalam Keperawatan. Salemba Medika. Jakarta

Notoatmodjo, S. 2012. Promosi Kesehatan Edisi Revisi 2012. Rineka Cipta. Jakarta

Notoatmodjo, S. 2010. Metodologi Penelitian Kesehatan. Rineka Cipta. Jakarta

Nurjannah, A. (2012). Personal Hygiene Siswa Sekolah Dasar Negeri Jatinangor. Students E-Journal, 1(1), 31.

Potter, P. A dan Perry, A. G. 2006. Buku Ajar Fundamental Keperawatan: Konsep, Proses dan Praktik Edisi 4. EGC. Jakarta

Saputra. 2013. Kebutuhan Dasar Manusia. Kompas Media Nusantara. Jakarta

Saryono. 2011. Kebutuhan Dasar Manusia (Catatan Kuliah). Nuha Medika. Yogyakarta

Sugiyono,2008, Metodologi penelitian Pendidikan, Alfabetha,Bandung

Susilo, S. 2011. Pendidikan Kesehatan dalam Keperawatan. Nuha Medika. Yogyakarta 